\title{
Olhar o Outro: Narrativas museológicas sobre a diversidade na época da globalização
}

\section{Looking at the Other: Museological Narrative on Diversity in the Era of Globalization}

\author{
Pedro Pereira Leite \\ Centro de Estudos Sociais \\ Colégio de S. Jerónimo. Largo D. Dinis \\ Apartado 3087. 3000-995 Coimbra, Portugal \\ pedropereiraleite@ces.uc.pt
}

Recibido: 1-04-2014

Aceptado: 30-07-2014

\begin{abstract}
Resumo
O artigo apresenta os resultados parciais duma investigação em curso sobra narrativas museológicas sobre o reconhecimento da diversidade cultural. A partir duma análise sobre os processos de construção a ideia do outro em diferentes exposições em diverso museus, na Península Ibérica, no Brasil e em Moçambique, procuramos identificar os processos narrativos hegemónicos e os processos de silenciamento e esquecimento da diferença. Argumentamos, a partir do discurso identitário português, que sem a inclusão das narrativas sobre a diversidade, a cultura hegemónica não está a fornecer uma cartografia mental adequada para orientar e enfrentar a construção de inovação social nos museus.
\end{abstract}

Palavras chave: Diversidade cultural. Inclusão social. Memória e Esquecimento. Culpa e Perdão. Alteridade.

\begin{abstract}
This article presents the partial results of a research about the recognition of cultural diversity on museum narratives. From an analysis of the formation of alterity on different exhibitions in several museums in the Iberian Peninsula, Brazil and Mozambique, we sought to identify the hegemonic narrative processes and the processes of silencing and forgetting the difference. We argue, from the Portuguese cultural speech that without the inclusion of narratives about the diversity culture does not provide a guiding mapping to address innovation.
\end{abstract}

KeY wORDs: Social Diversity. Social Inclusion. Memory and Forgetting. Guilt and Forgiveness. Alterity. 


\section{A construção da ideia social do outro}

O processo da construção da visão do outro é actualmente uma problemática relevante para $o$ campo da museologia. A função social da museologia é uma questão que o Movimento Internacional para uma Nova Museologia tem procurado afirmar como proposta de processos museológicos estabelecidos com base na voz às comunidades e na integração da diversidade cultural dos territórios. Defende-se uma museologia como espaço de encontro (Moutinho 1993).

Uma das críticas que tem sido feita ao paradigma positivista é a de que a investigação científica deixou de responder aos problemas das pessoas e das sociedades. A investigação científica é um processo de busca de conhecimento que se inicia com um questionamento sobre algo. A produção de ciência museológica deverá visar soluções para os problemas dos indivíduos, das sociedades, dos seus modos de relacionamento, entre si ou com a natureza. $\mathrm{O}$ conhecimento científico deve formular questões relevantes para problemas pertinentes (Santos 2006).

A questão da capacidade que cada comunidade tem para reconhecer o outro, o diferente, é uma das questões de relevância na produção do conhecimento museológico na Nova Museologia. Olhar e aceitar o outro é uma das questões que no âmbito da UNESCO é considerada como o princípio ético do tempo contemporâneo. Uma humanidade capaz de viver em paz, em segurança, na procura do bem-estar para todos e todas, mediante a educação, a ciência, a cultura e as comunicações constitui-se como o grande desígnio da ação humana. O interrogar como e de que forma as narrativas museológicas integram as narrativas sobre o outro torna-se assim uma questão de relevância para a museologia, quando se interroga sobre a sua Função Social.

A questão da operação mental que leva ao reconhecimento do outro e da diversidade é uma questão da maior relevância para as nossas instituições de memória. A origem do si mesmo, do individuo como ser consciente, resulta das perceções e das sensações dos órgãos do corpo. A consciência de que o eu é algo separado dos objetos exteriores. Uma consciência que tem um corpo, que coexiste com outros seres, igualmente vivos, e com o ambiente. Esta perceção do eu em relação com os outros é uma das características que nos distinguem, como espécie humana, das outras espécies.
Cada um de nós é simultaneamente indivíduo e parte do grupo. Cada um de nós transporta simultaneamente uma personalidade individual e uma personalidade social. A personalidade individual é o que nos distingue do mundo, uma identidade; enquanto a personalidade social constitui-se nas relações entre os indivíduos no grupo. Como se tratam de relações, tudo acontece no tempo e no espaço. O tempo vai moldando o papel de cada um no grupo e a relação de cada um com o seu corpo, enquanto o espaço referência o lugar que cada um ocupa em relação aos outros.

Também sabemos, que nas relações do indivíduo com o grupo social, a linguagem é fundamental. A linguagem é aqui abordada como todos os processos que permitem a ocorrência de comunicação, seja através movimentos, de sons ou de representações simbólicas. A capacidade da comunicação mediar, regular as ações e permitir condutas intencionais, é um instrumento indispensável aos processos sociais. A palavra é como sabemos uma característica da condição humana. A linguagem permite ao indivíduo preparar os seus atos e reportar a sua experiência. É através da linguagem, verbal e não-verbal, que cada um se vai regulando no mundo.

Através desta regulação da comunicação processam-se as hierarquizações entre os diferentes membros do grupo. A comunicação permite o estabelecimento de conexões entre os indivíduos, onde cada um se posiciona em relação ao outro em função do seu papel no grupo. Cada ato comunicativo é uma parte desse processo. Cada ato acontece no espaço e transporta um determinado valor. Um valor de relevância que confere uma determinada posição nas escalas simbólicas partilhadas na comunidade. A ritualização dos processos comunicativos, para além de manterem as conexões, afeta também o posicionamento de cada ato comunicativo no conjunto.

Esta questão é relevante no nosso caso para entender a forma como se constrói a ideia do outro. O grupo social é constituído pelos membros do grupo, os que são, e os que não são. A operação de disjunção que permite incluir e excluir é pois fundamental para a gestão da coesão do grupo. A relevância desta questão para o nosso trabalho advém desta característica, em que o que somos, como grupo também inclui os outros como grupo. E tudo isso está em contexto em permanente transformação.

A implicação da ideia do que somos é também o que não somos assume uma elevada re- 
levância no processo de formação dos elevados ideais das organizações internacionais que temos vindo a construir como Património Comum da Humanidade. A consciência da unidade da humanidade na sua diversidade. A consciência que para continuarmos a ser temos que aceitar igualmente as condições de existências daqueles que não sendo como nós, fazem parte da nossa diversidade no mundo.

Como é que as nossas sociedades e as nossas instituições de memória constroem esta relação entre a unidade do ser na sua diversidade. A análise do processo como os europeus construíram a ideia da diferença pode ser particularmente útil para entender esta problemática. As nossas fontes escritas e pictográficas para o século XVI são particularmente ricas para entender a forma como o aparelho mental europeu olhou o outro.

Em 1982, Alfredo Margarido no colóquio "O Humanismo Português na Europa, (Margarido 1984)), realizado um Paris, pelo Centro Cultural Português, analisa a forma como a visão do outro foi construída. Aqui o outro era o africano e o índio americano, seres diferentes do que então era conhecido pelo Mundo Mediterrâneo.

A africano era já conhecido deste mundo mediterrâneo devida às suas intensas relações com o Magreb. O que Alfredo Margarido procura analisar é como esse mundo que os europeus contactam é revelado através da viagem que dele constroem. Nas viagens produziu-se um encontro com outros seres humanos portadores de outras cosmogonias. A procura das inquietações que foram percecionadas perante o desconhecido e recensear essas as respostas constituiu o trabalho proposto.

Através da análise das imagens, dos desenhos dos livros de viagens, pois os textos são parco em descrições, Alfredo Margarido fez a reconstrução da rede de leitura do outro através das perceções e das intuições primeiras, expressas nas imagens. A busca do sentido do olhar, a procura dos sabores dos alimentos, as cores e os odores dos sítios são indicadores sobre a diferença: da terra, das plantas, dos animais, e sobretudo dos outros humanos.

Segundo Margarido, a língua de comunicação, as roupas, a alimentação, e os comportamentos fornecem num primeiro momento os dados necessários para construir as diferenças. É através dessas diferenças que se procura explicar e interpretar o outro. Procurar entender o outro no quadro das suas ações.

Como vimos mais acima, o processo de criação de identificação social é feito não só no estabelecimento de conexões, mas também de hierarquias. Neste artigo a autor defende que o reconhecimento da diferença é uma ação que permite potenciar o eu. Mostra que o tipo de relação que se estabelece com a alteridade, a sua aceitação e a busca de processos de diálogo se constitui como um caminho de elevado potencial para a criação da racionalidade ocidental. Igualmente demonstra que foi a recusa em incorporar essa diferença que conduziu à ausência de comunicação, e ao estabelecimento de uma relação de dominação de uns sobre os outros. Essa operação permitiu nessa altura, por exemplo, do tráfico negreiro.

A questão de não reconhecer o outro como portador duma inteligibilidade própria, não reconhecer a autonomia do outro cria, segundo Margarido, um deficit de identidade. Como afirma o autor a descoberta e a construção do outro é um processo de construção duma inteligibilidade permanente. No século XVI, a construção da leitura do outro estava condicionada pelas características do pensamento do tempo. Escreve o autor

"O outro não é um dado preconcebido. Ele devia ser adquirido e construído à medida que se prosseguia a comunicação. Algumas vezes não era possível estabelecer comunicação, e não é possível prosseguir com o processo de identificação. O outro fica com um nó irresolúvel. Perante o impasse, muitas vezes é necessário eliminar o outro, mesmo fisicamente, para recuperar da instabilidade que a sua presença gera (Margarido 1984: 507).

O pensamento humanista europeu, conclui o autor, num primeiro momento foi capaz reconhecer a diferença do outro e dos outros espaços. Através da análise das imagens é possível entender que essa diferença foi prececionada. Contudo, o processo que desencadeou, acabou por impedir a continuidade da percepção dessa diferença e acabou por reduzir, quer o outro, quer os seus espaços a coisas. Ao ser negada a entidade ontológica ao outro, ele foi apropriado como um objecto. Tornou-se uma mercadoria. Estamos portanto perante um pensamento que constrói uma visibilidade e oculta, através da negação, a diversidade. Esta distinção entre o visível a quem é atribuído valor ontológico, e o invisível, a quem é negado esse valor é um das características do pensamento ocidental (Santos 2011). 
A natureza das relações dos grupos humanos tem por base a interação do individuo com o grupo em contexto comunicativo. Essa relação gera situações de competição e cooperação. No primeiro caso verifica-se a afirmação do indivíduo ou dos grupos face aos rivais; enquanto no segundo caso se verifica a afirmação das relações de mutualidade e entre ajuda. Como a história nos tem ajudado a verificar, do equilíbrio entre as relações cooperativas e de competição, depende a sucesso e a sobrevivência da espécie. A relevância do reconhecimento do outro insere-se no âmbito destas problemáticas.

Em síntese, o nosso paradigma epistémico, ao estar baseado na distinção entre o sujeito e o objeto, entre o objetivo e o subjetivo, entre o visível e o invisível, tem vindo a favorecer as relações de competição em detrimento da cooperação. Trata-se dum processo de conhecimento orientado para a ação, para o domínio do outro e do mundo. Ele forma-se a partir do século XVI e tem servido como base de transformação do mundo. O conhecimento científico é uma importante ferramenta das nossas sociedades, fornecendo indicações muito claras e seguras sobre os caminhos a percorrer, sobre os procedimentos a tomar para a transformação da natureza. Trata-se dum bem precisoso, mas não está isento de defeitos, aos quais devemos estar atentos. Um deles é o de nem sempre favorecer a cooperação com os outros.

O discurso científico, fornece o roteiro da transformação do mundo. Um discurso que procura iluminar o que está na sombra, para usar a metáfora da alegoria da caverna usada por Platão. Nesse discurso a razão é o instrumento. É a razão do conhecimento científico que leva à afirmação duma linha entre o que é objetivo e subjetivo. A afirmação deste valor da objetividade e a negação da subjetividade é o que permite a operação mental de afirmação da apropriação da natureza e da violência sobre o outro através da negação da sua ontologia. A impossibilidade da copresença do outro gera a sua ausência. O não reconhecimento do outro leva a representações de afirmação da dimensão identitária da unidade e à recusa a pluralidade da diferença. A partir da análise das narrativas identitárias como lugares de competição ou de cooperação dos grupos, podemos verificar o grau de inclusão ou exclusão da diferença e de alteridade.

\section{O reconhecimento da narrativa do outro: o caso do luso tropicalismo}

O luso tropicalismo é um dos mitos sobre a condição portuguesa que foi amplamente usado no século XX para justificar a ação colonial em África pelo Regime do Estado Novo português. Usamo-lo aqui como exemplo ilustrativo da evolução da construção da imagem do outro na cultura portuguesa.

Todas as culturas constroem imagens de si. Uma imagem de si, como sabemos é uma relação identitária que contem sempre a inclusão (o que está dentro), a disjunção (como separa) e a implicação (que define as regras de relação).

Todas as narrativas míticas transportam discursos indicadores sobre as formas de pertença, sobre as condutas de manutenção dessa condição, bem como os diversos sistemas de exclusão. Esse é um discurso que vai variando ao longo dos processos históricos em função das justificações do presente.

No caso do Brasil, uma das novas nações construídas na América do Sul, a partir da autonomização da condição colonial, podemos, grosso modo verificar esta evolução através das suas narrativas identitárias. O discurso naturalista presente em Iracema (Alencar 1994), aponta para uma relação primordial onde as populações ameríndias que viviam num estado natural, como o bom selvagem de Jean Jacques Rousseau (1977). Este estado de inocência é quebrado através da sua relação com os colonizadores. São estes que transportavam a "luz" da civilização, e que lhes permitiu ascender a uma condição superior. Estamos perante um processo em que a nova nação se legitimava no espaço do outro por via da missão superior do colono.

Para essa matriz identitária contribuirá o antropólogo Gilberto Freyre, em 1934, ao defender que a natureza pacífica da nação brasileira era devido à convivência das "raças". O convívio pacífico entre as raças tinha permitido o surgimento do mestiço (Freyre 1957), uma nova espécie que reunia as virtudes de cada raça constituinte. O antropólogo procurava demonstrar, pela análise do espaço residencial, que a colonização portuguesa no Brasil pelos portugueses e o transporte de negros escravos no Atlântico tinha acabado por favorecer ambas as raças. Um favorecimento que foi alcançado pela convivência pacífica entre 
brancos e negros. A Casa Grande, onde vivia o senhor e a Sanzala, o espaço dos escravos, não eram espaços herméticos, mas sim fluidos.

A tese do antropólogo, que virá a ser tardiamente adotada em Portugal, como último recurso de argumentos contra a independência das suas colónias africana, é de que a colonização portuguesa no Brasil tinha sido "bondosa". Essa ação tinha permitido a miscigenação.

A questão a construção do novo como algo que supera a soma das partes é uma questão é relevante para entender a matriz do discurso identitário português. Cada identidade vai-se afirmando a partir das especificidades da observação do narrador, das referências e objetivos desse mesmo narrador. O campo de compreensão e de explicação de cada um dos narradores parte do seu presente. A preocupação sobre o tempo presente é influenciada pela vontade de transformação. Trabalhar sobre os discursos identitários é trabalhar sobre fenómenos de representação. Olhar como o outro emerge ou é esquecido, é uma medida de análise da aceitação da alteridade.

No caso português, a sua relação com o outro é uma relação complexa. Noutro local demos conta da evolução desta relação nos seus tempos históricos (Leite 1997). Argumentamos então que registamos três períodos. O da "espírito de cruzada", o da "missão civilizadora" e o do "lusotropicalismo".

Grosso modo, o "Espírito de Cruzada", marcou o tempo moderno, mediado pelas navegações henriquinas e a independência do Brasil Foi o tempo em que os marinheiros e mercadores, com uma espadas numa das mãos e a cruz de Cristo na outra, a pretexto de "dilatar a fé e Império" se envolveram no trato mercantil entre a Europa, as Américas, as áfricas e os orientes.

A "Missão Civilizadora" emerge como narrativa identitária com o fim do Império e o fim da exclusividade do comércio luso-brasileiro, em 1818. Ultrapassada a crise económica e social que sucedeu à implantação do liberalismo e às guerras peninsulares, na segunda metade do século XIX, os portuguese lançam-se na ocupação do sertão africano. Até meados do século XX tinha como missão civilizar os selvagens.

Após o final da segunda guerra mundial, e a emergência duma nova ordem em Yalta, duas novas potências emergem no Mundo. Os Estados Unidos e a então União Soviética. Em 1945, com a criação das Nações Unidas, estas duas potências, a primeira antiga colónia inglesa, a segunda interessada em expandir a sua área de influência, levam a um questionamento dos mandatos e da natureza dessa missão civilizadora. Inicia-se o processo de descolonização, que em vinte anos transformará África num continente de nações independentes.

É neste contexto que o luso tropicalismo é relevante com mito identitário português e se constitui como base ideológica que fundamenta a pretensão portuguesa de manter o seu domínio colonial intacto. Para além dos direitos históricos, duma presença de quinhentos anos, a diplomacia portuguesa irá ensaiar uma resistência à nova ordem internacional, adicionando à ancestralidade a especificidade duma suposta essência de ser português. Uma essência alicerçada no discurso científico. Os portugueses tentam convencer a Comunidade Internacional que a sua obra nestes territórios tinha levado à criação dum homem novo. Um ser luso-tropical. Um ser mestiços, adaptado a estes espaços, mas espiritualmente ligados à terra lusitana, sua fonte maternal.

A teoria de Gilberto Freyre era indicada para esse esforço de demonstração. O regime político encomenda ao sociólogo uma viagem pelo império, à procura desse novo ser. Esse trabalho está documentado em vários relatórios publicados (Freyre 1964). No fundo o que é feito é uma transição da teoria aplicada no Brasil, sobre a especial aptidão do homem português em estar nos trópicos e em misturar-se com as mulheres indígenas a quem faz filhos mestiços e crioulos. Para validar essa teoria, o autor não hesita em apontar casos onde esse homem já se tinha concretizado: os crioulos de Cabo Verde, os Moçambiques da Ilha de Moçambique e os Goeses de Goa na Índia, então portuguesa.

Tratava-se naturalmente duma Política de Estado, que tinha como objectivo, usar a ciência social, para fundamentar e assegurar o domínio destes territórios. Admita-se implicitamente que todos eles se viriam num futuro distante a dispor da suas "autonomias", como tinha sido o caso do Brasil. Defendia a diplomacia portuguesa que era necessário mais tempo para concluir a missão civilizadora e que dada a especificidade da ligação espiritual, estes territórios faziam parte duma comunidade ao contrário das outras colónias europeias. Em 1974 essa politica colapsou.

Contudo, o que é para nós relevante é relação complexa que o luso tropicalismo estabelece com o outro e que vai prosseguir nos vários discursos identitários. Essa ideia de comunidade espiritual e de valores parte duma matriz original lusitana. Ela evolui até atingir os valores espirituais e 
recusa da entidade ontológica do outro. O lusotropicalismo é uma relação num sentido único onde a matriz portuguesa, vista como superior, á absorvida pelos outros, mestiçando-se. São estes novos seres, crioulos, portadores da espiritualidade cristã e da técnica europeia, uma relação que os adapta fisicamente às difíceis condições do sertão africano. Tratam-se de diálogos desiguais que cria uma ambiguidade não completamente resolvida. No luso tropicalismo, o europeu ainda que seja sempre culturalmente dominante, necessita que o outro tenha uma presença. Ainda que dominado emerge uma identidade que não pode ser reconhecida e pode gerar vários equívocos.

$\mathrm{Na}$ formulação da teoria do luso tropicalismo de Gilberto Freyre, o luso tinha capacidade específicas para se adaptar aos trópicos e de se misturar com as populações locais, criando as tais comunidades multirraciais (Freyre, Casa Grande e Sanzala 1957). A efabulação sobre o modo como os portugueses se relacionam com os outros, levava a idealizar uma relação de dádiva pacífica. $O$ superior passa algo ao inferior que o aceita com agradecimento, porque lhe reconhece o valor. Não à trocas.

Segundo Gilberto Freyre, esta capacidade dos Portugueses eram inatas e derivavam do fato do próprio substrato étnico dos povos peninsulares ser resultado da incorporação de genes árabes e berberes. Os portugueses nos trópicos transportavam ainda uma visão "espiritual". Uma visão superior construída com base no cristianismo monástico. A condição luso-tropical é uma visão superior do mundo onde os lusitanos são os missionários duma nova cristandade assimilada.

Embora concebida como discursos identitário aplicado á questão colonial, a visão desta narrativa deixou marcas nos processos como os portugueses se relacionam com o mundo. Sobretudo com os outros e com alteridade. Isso é visível, por exemplo na política da língua (Margarido 2000).

Apesar desta formulação sobre o outro, o luso-tropicalismo, por partir dum pressuposto da qualidade superior da sua matriz original, de um certo estado de pureza genética, ele não é capaz de reconhecer a visão do outro ontológico fora da ação espiritual. Esta aproximação ao outro é sempre incompleta porque não é dialógica. O luso tropicalismo justifica o processo de assimilação, mas essa assimilação é um caminho de via única. Continua a ser um trânsito entre um pré-condição ou estado natural e o progresso, construído pela civilização e dado pela elevação espiritual (Castelo 1998).
Poderíamos pensar que após o fim do colonialismo português em África, este pensamento identitário se tivesse dissolvido. No entanto, como mais adiante verificaremos, a propósito de outras culturas peninsulares, ele ainda está presente na matriz identitária dos portugueses, impedindo-os de dialogar com a alteridade.

A visão do outro enquanto operação do pensamento, como categorização, é um processo de formação dum valor. $\mathrm{O}$ valor é uma operação pensamento de atribuição de relevância que contextualiza um determinado objeto no espaço, no tempo e em relação. Cria limites, distinções e a acentua posições. Nesse sentido o valor é simultaneamente um fim e um instrumento.

Como verificamos, a construção da imagem do outro, quando é feita através da confrontação, implica a existência de atitudes de exclusão. A exclusão leva a recusa do reconhecimento da entidade ontológica do outro, à negação da sua história e legitima a violência sobre estes. No passado essa exclusão foi feita com base em atributos, como a cor da pele, a religião, as tradições, as categorias do conhecimento. Nos dias de hoje é feita pelo silenciamento, pela manutenção do esquecimento.

Nos dias de hoje sabemos que ao invés da confrontação devemos incluir o outro na sua diversidade para criar implicações. A inovação emerge da incorporação do que é novo. A diversidade é um valor da própria nossa própria riqueza. É através desse encontro com o outro, com a diversidade que nós nos reconhecemos, que nós encontramos os nossos limites e construímos das nossas adaptações ao novo.

A capacidade de entender o mundo como um espaço partilhado por todos e onde todos se podem expressar na sua diversidade representa um dos novos valores da humanidade. Um valor que resulta da progressiva consciência da necessidade de regular as atividades e as relações entre os grupos humanos.

Olhar o outro torna-se uma componente duma adaptação dos seres e dos grupos e uma possibilidade de transformação virtuosas. Olhar o outro é uma possibilidade de ser ou não ser livre e inovador. Olhar o outro é um exercício de pensamento divergente, o pensamento que permite incluir a diversidade dos saberes como forma de olhar para diferentes formas de resolução de problemas (Santos 2006).

Neste contexto, olhar para a diversidade das narrativas sobre os outros nos museus é um exercício que permitirá caracterizar as formas de pen- 
samento dominante na sociedade. Através dele será possível identificar as relações de reciprocidade e de expansividade que conduzem à cocriação nos museus e entender de que forma estão a trabalhar os processos patrimoniais.

\section{O outro nas narrativas museológicas na fronteira luso-estremenha}

A procura das relações de reciprocidade nos espaços museológicos orientou a formulação da problemática da nossa pesquisa. Trata-se duma pesquisa em processo. Os seus resultados são provisórios. Ele desenvolve-se em quatros espaços diferenciados. Portugal, em Espanha, no Brasil e em Moçambique. São quatro espaços que se encontram ligados por fenómenos comuns, nos quais a escravatura e o tráfico negreiro constituem um eixo estruturantes.

Não cabe no espaço deste artigo apresentar a totalidade dos resultados das nossas investigações. Uma parte destes trabalhos tem vindo a ser preliminarmente publicados sob a forma de "Diários de Viagem", prevendo-se que a apresentação do relatório de investigação. Neste processo de investigação estamos particularmente atentos à forma como as narrativas museológicas apresentam a inclusão de outros grupos que habitam ou habitaram os espaços culturais, para procurar entender de que forma se vão criando diálogos com outros saberes.

No caso de Portugal e Espanha onde agora centramos a nossa análise, optamos por olhar para as representações região da fronteira estremenha ${ }^{2}$. Focamos particularmente para representações de dois grupos de heranças culturais: As heranças africanas e ciganas. No primeiro caso temos vindo a desenvolver diversos trabalhos integrados no Comité Português do Projeto UNESCO "A Rota do Escravo"3. Veja-se nomeadamente (Henriques I. d., A Herança Africana em Portugal, 2008) e (Henriques, Leite, Fantasia 2013). O caso das heranças ciganas nos museus, é um assunto que nos mercê alguma reflexão, no âmbito deste nosso propósito de olhar o outro nas narrativas dos museus. São dois grupos que se encontram ausentes nas representações dos museus. São memórias que não são narradas. Vozes que se mantém no silêncio.

A questão dos africanos, em Portugal e em Espanha é uma questão que merece algum detalhe no seu tratamento pois estamos perante dinâmicas histórias diferenciadas, embora por vezes mutuamente influenciadas ${ }^{4}$. Trata-se dum fenómeno que adensa o silêncio sobre uma memória esquecida. Deixaremos o seu tratamento para outra altura.

A questão dos ciganos suscita-nos algumas reflexões mais profundas. Em Portugal, no final do século XIX, encontramos os primeiros estudos sobre as populações ciganas através do estudo dos linguistas. Em 1879, Teófilo Braga insere nas suas Lições sobre Positivismo um capítulo "Origens dos Ciganos" (Braga 1879) e seis anos mais tarde, outro linguista Adolfo Coelho faz um estudo sobre o Calão, a língua cigana em Portugal. (Coelho 1995 [1892]). Trata-se de dois autores que procederam à recolha de contos e lendas tradicionais. A temática cigana, a partir da especificidade pela diferença deve ter merecido a relevância destes autores pela sua visibilidade na sociedade. Adolfo coelho aprofunda até o seu trabalho ao estudo etnográfico e à sua diáspora cigana no Brasil, local para onde muitos ciganos tinham sido exilados.

No final do século, outro autor, Rosa Peixoto será autor de um artigo sobre "Os ciganos em Portugal" (Peixoto 1897) a partir do caso das comunidades piscatórias do norte, uma zona de elevada densidade de ciganos. $\mathrm{O}$ assunto dos ciganos será retomado por Leite de Vasconcelos, num trabalho que só será publicado postumamente na revista "Etnografia Portuguesa" (Vasconcelos 1958). Estamos perante um conjunto de autores para quem a presença do outro mereceu relevância.

Com a democratização a questão cigana emerge como um fenómeno de análise. Para além da questão da diferença, seja na língua, seja nos costumes e tradições, que o campo da antropologia trabalha (O'Neill 2003) e (Afonso 2012), a área da sociologia e da assistência social vai trazer à discussão a questão numa perspetiva de integração e de estudo de minorias (Mendes 2012) e (Bastos 2012).

A presença e a diferença da comunidade cigana em Portugal levantou durante esses anos a questão da sua integração nas estruturas sociais maioritárias. A questão da habitação, da educação, da saúde, da atividade profissional, sobretudo do comércio ambulante e da segurança foram assuntos abordados, quer em termos de inclusão social, quer em termos de relação com as mino- 
rias. Uma questão que de resto é também comum em Espanha (Adelantado 1994).

$\mathrm{O}$ que nos parece relevante para o estudo da memória e da herança das comunidades ciganas da península, no âmbito desta nossa análise sobre o outro, situam-se em dois eixos de análise: $\mathrm{O}$ processo de Mendes, produção e memória social da comunidade cigana, e os modos como as comunidades maioritárias olham para estas memórias. No primeiro caso temos a sua resiliência cultural como fenómeno relevante, no segundo caso a sua ausência nas instituições de memória hegemónicas, mantendo-se a sua transmissão pelos processos tradicionais existentes na comunidade.

A entrada nos territórios Ibéricos da comunidade cigana está documentada desde o século XIV. Várias referências dão nota dos conflitos existentes em diferentes lugares. Os ciganos foram alvo de diversas perseguições e procedimentos administrativos para inclusão nas normas dominantes. Sabemos como resistiram à integração e como mantiveram, nessas condições a sua identidade. A par com os Judeus e Mouros, foram um dos grupos mais ativamente perseguidos. A sua diferença era um dos elementos de estigma. Muito foram condenados às minas onde acabavam por morrer ao fim de poucos meses "azougados". Por exemplo, nos arredores de Cáceres, existiam no final do século XIX várias minas. Hoje, dentro da cidade, há um Bairro situado numa dessas antigas zonas mineiras - a aldeia morena - que mantem o nome que o associa a uma população mineira e cigana. Na região o termo moreno é associado ao cigano.

A cultura cigana é um elemento complexo da cultura hispânica. Misto de atração e repulsa. Por exemplo o flamenco como canto gitano não deixa de exercer um fascínio sobre a matriz da cultura andaluza. Tal como alias se verifica na Rumba Catalã, para onde emigraram no final de século XIX, populações da costa valenciana ou levantina.

$\mathrm{O}$ que nos parece relevante para os trabalhos sobre as heranças ciganas são os modos e processos de transmissão da memória que tem permitido à comunidade manter alguns dos seus traços identitários. Com efeito se a língua cigana, o Caló, deixou de ser usado com instrumento de comunicação, subsistindo apenas em nomes, por outro lado as festas ciganas mantêm a sua vitalidade. A Romería Gitana de la Virgen de los Remedios, em Fergenal de La Sierra, Cáceres reúne, no final de outubro uma comunidade que veem de vários pontos da Espanha e Portugal. Estamos perante uma comunidade que encontrou modos de manter a sua memória, ajustando-se a diferentes dinâmicas.

Ao olhar para as narrativas patrimoniais nos museus verificamos que esta herança não está representada. A regra da matriz identitária, numa linha cronológica, inicia-se na idade da pedra, absorve os povos do mediterrâneo e do norte da europa que trouxeram os modos de trabalhar os metais e introduzem as escritas ibéricas. Chegam os romanos e os árabes, constituem a matriz que não admite intrusos. A partir daí a narrativa torna-se sincrónica e etnográfica. A diversidade é mostrada nos territórios, criando uma imagem únicas, sem diversidade interna. Em regra, mesmo nos locais onde a comunidade cigana é expressiva, não há representações da sua cultura ${ }^{5}$. Os ciganos, tal como os africanos, parecem em nada ter contribuído para a cultura ibérica malgrado o reconhecimento da sua matriz no flamenco e nas sevilhanas.

Apesar da sua presença silenciosa no tecido urbano nas nossas análises sobre os patrimónios e heranças nas narrativas das minorias dos museus de fronteira, não encontramos representações sobre estes "estranhos" habitantes.

Mesmo na fronteira há fronteiras construídas nos silêncios. O silenciamento do outro é um silenciamento dos nossos caminhos e das nossas opções. Trata-se dum fenómeno comum aos dois lados da fronteira. É certo que não podemos generalizar. Conhecemos casos onde a memória e a herança cigana foi alvo de exposições temporárias. Mas isso são mais as exceções que confirmam a regra.

\section{A questão do silêncio e do esquecimento}

Concluindo as questões que nos têm orientado, a questão do silêncio e do esquecimento do outro na âmbito da construção das narrativas museológicas, vale a pena refletir sobre os casos que apontamos, não para criticarmos os procedimentos, mas para pensarmos sobre os seus significados. O processo de silenciamento está baseado na negação da identidade ontológica do outro. $\mathrm{O}$ silêncio é todavia um poder emergente. Ele estando esquecido, não é mais do que algo que existe sem ser nomeado. A qualquer momento pode irromper.

O reconhecer a ausência das heranças dos outros nos museus implica refletir sobre o modo como as narrativas museológicas são construídas. 
Quem escolhe, o que escolhe e como se escolhem os patrimónios e as heranças. Essas são questões relevantes pra uma museologia inclusiva. Mas nestes casos não basta acentuar a necessidade de participação. É necessário que os membros dessas comunidades dialoguem com os espaços museológicos para que dessa troca de olhares se criem formas de trabalho sobre o património que favoreçam o encontro.

Esta questão leva-nos finalmente a uma última questão: a da culpa e do perdão. São temas complexos, que Paul Ricoeur aborda no seu trabalho "A Memória, a História e o Esquecimento" (Ricoeur 2008). Um tema que surge no epílogo da sua obra, de reflexão sobre a epistemologia da história e das suas conexões aos estudos da memória coletiva e do esquecimento.

Neste trabalho de Paul Ricoeur sobre a Memória Coletiva, o passado é revelado pelas suas representações. A hermenêutica da história é um estudo sobre as representações. $\mathrm{O}$ autor distingue a História e a Memória Coletiva. O Estudo do passado, campo da história, contem partes que são inacessíveis no presente. Há uma impossibilidade formal de reconstituir a totalidade. Há no entanto traços desse passado que chegam até nós, como documentos, testemunhos, ou outros artefactos e sonoridades. São objetos que se constituem como um eco de fragmentos que chegam até ao presente. É certo que o historiador pode, através da sua ação, alargar a pesquisa desses fragmentos, adicionando mais fragmentos. No entanto, toda a coleta constitui-se como feixes de possibilidades, sobre os quais reconstruímos os seus sentidos.

O autor considera a possibilidade da memória social ser um instrumento de análise desse passado. A memória, como operação cognitiva, é naturalmente seletiva. Apresenta incongruências e falhas nas suas representações. Ele resulta da captura de significâncias. Por isso mesmo, como parte do passado, ela contém as relevâncias e simultaneamente a sua negação. O que está esque- cido está dessa forma ligado ao que é rememorado, como contexto. É aqui que o destaque que Ricoeur dá ao Esquecimento e ao perdão merece ser destacado (Ricoeur 2008: 423). Não se trata aqui da questão do esquecimento como olvido por ausência de relevância. Mas sim da questão do esquecimento como silenciamento. Como um fenómeno do que tendo sido, deixou de ser. São fenómenos que se manifestam de formas silenciadas. Para além de poderem ser alvo do trabalho histórico, o esquecimento transporta uma parte de memória coletiva que está pressentem em todos os indivíduos.

A condição histórica de um ser é de existir em contexto. A condição história duma comunidade ou dum grupo é o resultado da interação dos seus membros. Cada um é simultaneamente herdeiro e utilizador das memórias sociais. Cada comunidade existe no tempo e aquilo que valoriza é resultado desse contexto. A ideia da culpa e do trauma são manifestações do passado no presente.

Sem a consciência da culpa não há reconciliação com esse passado. Sem reconhecimento da culpa não é possível reconhecer os traumas e não há perdão. Sem perdão não há possibilidade de futuro.

A recusa no reconhecimento da autonomia ontológica do outro, tal como encontramos nas diversas narrativas museológicas traduz a persistente incapacidade dessa memória coletiva de reconhecer e tomar consciência do seu passado e reconhecer a diversidade do eu presente. Essa incapacidade de renovar as suas narrativas sobre o passado dá origem à fragmentação do passado.

As velhas narrativas emergem por entre os velhos objetos dos museus, criando espirais narrativas que dificultam o entendimento do presente. Os novos discursos acabam por revelar fragmentos do passado e criam impasses no entendimento do presente. Essa dificuldade em entender o presente conduz ao bloqueamento da inclusão de novas narrativas e no entendimento dos grandes desafios coletivos.

\section{Notas}

1. Veja-se em http://globalherit.hyotheses.org

2. Por esta análise temos vindo a recolher informação no âmbito daa Plataforma Transfronteiriça de Museus, um grupo que tem vindo a promover encontros e iniciativas entre os museus da Raia desde 2004.

3. URL:http://pascal.iseg.utl.pt/ cesa/rotadoescravo/?page_id $=22$

4. Estamos por exemplo a falar das colónias de criação de escravos que existiam no Alentejo, no sul de Portugal, que exportavam "machos" para as minas de Almadem (Marques 2004). 
5. Dados os limites regionais da nossa análise, estamos a referir-nos à região da Fronteira Estremenha, da Beira e do Alentejo.

\section{REFERENCIAS BibLIOGRÁFiCAS}

Adelantado, A. G. (1994): Un grupo étnico en medio urbano: gitanos en la ciudad. Tesis Doutoral.

Afonso, A. I. (2012): Etnografias com Ciganos. Colibri, Lisboa.

Alencar, J. DE (1994): Iracema: Lenda do Ceará. Almedina, Coimbra.

Bastos, G. P. (2012): Portugueses Ciganos e Ciganofobia em Portugal. Colibri, Lisboa.

Braga, T. (1879): Origem dos Ciganos. O Positivismo.

Castelo, C. (1998): O Modo Português de Estar no Mundo. Afrontamento, Porto.

Coelho, A. (1995 [1892]): Os Ciganos em Portugal. Publicações Dom Quixote, Lisboa.

Febvre, L. (1968): Le Problème de L'Incroyance au XVI Siècle. Albin Michel, Paris:

FreYre, G. (1964): Aventura e Rotina. Livros do Brasil, Lisboa.

Freyre, G. (1957): Casa Grande e Sanzala. Livros do Brasil, Lisboa.

Henriques, I. De (2008): A Herança Africana em Portugal. CTT, Lisboa.

Henriques, I. DE; Leite, P. P.; Fantasia, A. (2013): Lisboa Africana: Percursos de Lugares de Memória da Presença Africana. Marca D’Agua, Lisboa.

Holanda, S. B. (2007): Raizes do Brasil. Companhia das Letras, São Paulo.

Leite, P. P. (1997): A Escola na Sanzala: Imagens da ação educativa colonial no Estado Novo. Universidade de Lisboa: Dissertação de Mestrado em Ciências da Educação Faculdade Psicologia e Ciências da Educação.

Margarido, A. (1984): La vision de l'autre (africain et indien d'Amérique) dans la Renaissance Portugaise. L'Humanisme Portuguais dans L'Europe (pp. 507-555). Fundação Calouste Gulbenkian, Paris.

Margarido, A. (2000): A Lusofonia e os Lusófono : Novos Mitos Portugueses. Edições Universitárias Lusófonas, Lisboa.

Marques, J. P. (2004): Portugal e a Escravatura dos Africanos. ICS, Lisboa.

Mendes, M. M. (2012): Ciganos: Identidades, Racismo Discriminação. Caleidoscópio, Lisboa.

Moutinho, M. (1993): Sobre o conceito de Museologia Social, in Cadernos de Sociomuseologia, ${ }^{\circ}$ 1, ULHT, Lisboa: 5-7.

O’ NeILl, A. (2003): Os Ciganos Portugueses: uma aproximação antropológica. CRIA.

Peixoto, R. (1897): Os Ciganos em Portugal. O Poveiro.

Ribeiro, D. (1997): O Povo Brasileiro. Companhia das Letras, São Paulo.

Ricoeur, P. (2008): A memória, a história, o esquecimento. Unicamp, Campinas.

Rousseau, J. J. (1977): O Contrato Social. Editorial Bertrand, Lisboa.

SANTOS, B DE S. (2000): Crítica da Razão Indolente: contra o desperdício da experiencia. Afrontamento, Porto.

Santos, B. De S. (2006): Gramática do Tempo: Para uma nova cultura política. Afrontamento, Porto.

Vasconcelos, L. de (1958): Os Ciganos: Origem e sua presença em Portugal IV. Etnografia Portuguesa. 